\title{
A Summary of the Research on the Relationship Between Financial Development and Economic Growth from the Perspective of National Differences
}

\author{
Wang Xiaoping ${ }^{1, a,{ }^{*}, \text { Liu Min }}{ }^{2, b}$ \\ ${ }^{1}$ Shanghai Business School, Shanghai, China \\ ${ }^{2}$ Shanghai Cultural Radio Film and Television Group Co., Ltd., Shanghai, China \\ achyshx@126.com, ${ }^{\mathrm{b}}$ liumincathy@126.com \\ ${ }^{*}$ Corresponding author
}

Key words: financial development; economic growth; national differences

\begin{abstract}
The relationship between financial development and economic growth has always been a hot issue. From the perspective of transnational sample and single country sample, this paper summarizes the relationship between financial development and economic growth among different countries. Based on the existing literature, there are five relationships between financial development and economic growth in different sample countries: one-way relationship, mutual promotion relationship, non-linear relationship, negative relationship and no relationship. The article holds that there are two reasons why researchers draw different conclusions: one is that the research variables are different, the other is that the empirical models are different.
\end{abstract}

\section{国家差异视角下金融发展与经济增长关系研究综述}

\author{
王小平 ${ }^{1, a}{ }^{*}$, , 刘敏 $^{2, b}$ \\ ${ }^{1}$ 上海商学院金融系，上海，中国 \\ ${ }^{2}$ 上海文化广播影视集团有限公司，上海，中国 \\ achyshx@126.com, 'liumincathy@126.com3 \\ *通讯作者
}

关键词: 金融发展; 经济增长; 国家差异

中文摘要. 金融发展和经济增长关系的研究一直是热点问题。文章从跨国样本和单一国家样本 视角出发，就不同样本国家间金融发展与经济增长之间的关系进行了总结。基于现有文献， 不同样本国家的金融发展和经济增长之间存在五种关系，即单向关系、相互促进关系、非线 性关系、负向关系以及没有关系。文章认为, 研究者们得出了不同结论的原因有两方面: 一 是选取的研究变量不同, 二是实证模型不同。

\section{1. 引言}

自从Schumpeter（1912）提出金融发展能够促进生产力和经济发展水平提高的观点后, 国内外学者们就金融发展与经济增长的关系开始了大量研究。从现有文献看, 金融发展与经 济增长之间的关系可以分为四类: 一是金融发展与经济增长之间的单向关系，即金融发展促 进经济增长或经济增长促进金融发展，称为供给导向假设（Supply-Leading Hypothesis）或需 求跟进假（Demand-Following Hypothesis）; 二是金融发展与经济增长相互促进关系，即互动 
假设（Feedback Hypothesis）; 三是金融发展与经济增长是非线性关系; 四是金融发展与经济 增长之间没有因果关系, 即中性假设（Neutrality Hypothesis）; 五是金融发展对经济增长具 有负向关系 (Ang,2008; GFink et al. 2003; Pradhan,et al. 2016; 江春等, 2013; 于成永, 2016; 谢平安等, 2017)。

本文从不同样本国家视角出发，分析不同国家间金融发展和经济增长之间的关系。

从现有文献研究看, 分析样本国家分为跨国和单一国家。在跨国样本中, 最少的样本国 家为2个, 如Arestis \& Demetriades（1997）、Darrat（1999）; 最多的样本国家为146个, 如 Seven \& Yetkiner (2016)。有的文献研究发展中国家的金融发展和经济增长的关系, 如 Al-Yousif (2002) 、P.K. Narayan \& S. Narayan（2013）; 有的研究发达国家，如Gerhard Fink 等（2003）、Peia \& Roszbach（2015）；有的研究欧盟国家，如Kugler \& Neusser（1998）、 Rivaud-Danse \& Dubocage, Salais (2001) ; 有的研究非洲国家, 如Menyah等 (2014); 有 的研究中等收入国家, 如Nahla Samargandi等 (2015); 有的研究南亚国家, 如Khairulx Alom (2018); 有的是将低收入、中等收入和高收入国家统一在一起作为研究样本, 如Seven \&Yetkiner (2016)。

\section{2. 跨国样本研究}

跨国样本研究可分为 2 种类型, 一是样本国家是几十个甚至上百个, 国家类型多样; 一是 以某一类型国家为分析样本，如发达国家、发展中国家等。

\section{1 数量众多国家样本研究}

在这些研究中, 研究者一方面将样本国家的数量增加, 一方面使用各种不同的研究方法 对金融发展和经济增长之间的关系进行研究。研究者利用几十个甚至上百个国家数据进行分 析, 力争得到一般的研究结论, 但事实上, 研究者们得出的结论存在差异。

一部分研究者认为, 金融发展和经济增长之间存在正相关性。如Goldsmith（1969）利用 35 个国家1860-1963年的数据, 实证分析了金融发展和金融服务质量正相关。King \&Levine (1993) 则对80多个国家1960-1989年的数据进行了分析, 结果表明, 金融中介与经济增长之 间具有正的相关性。Levine等(2000) 则扩大了样本国家, 分别利用71个和78个国家1960-1995 年的的横截面数据和面板数据, 证明金融发展对经济增长具有正的因果影响。Levine, Zervos （1998）利用47个国家1976-1993年的数据, 通过构建跨国回归分析模型, 分析了银行中介和 股票市场与经济增长之间的关系, 结果表明, 金融部门与经济增长相互之间具有强的正的相 关性。Dilek Durusu-Ciftci等（2017）则在理论研究上有所拓展。在前人研究基础上，将金融 市场引入模型, 构建了Solow-Swan增长模型, 理论分析表明, 信贷市场和股票市场的负债是 人均GDP增长的长期驱动因素。作者利用40个国家1989-2011年的面板数据, 通过构建面板数 据模型, 借助共同相关效应和增强均值组方法进行了实证分析。结果表明, 信贷市场和股票 市场对人均GDP的稳定状态具有长期正向作用，信贷市场的作用更大。因此，发展金融市场 将促进经济增长。

Berthélemy, Varoudakis（1997）通过构建面板线性回归模型，利用85个国家1960-1990年 的数据，分析了金融深化和经济增长之间的关系。结果表明，金融深化对实际经济增长具有 负的相关性。而Hahn（2002）利用23个国家1970-2000年的数据, 通过建立在ARDL模型上的 面板误差修正方法，实证表明，金融发展与经济增长之间有着很小的因果联系。

但是, 有研究者认为, 金融发展和经济增长之间存在复杂的非线性关系, 金融发展并不 总是促进经济发展（曹强，2014）。如Law \& Singh（2014）认为，金融发展和经济增长之间 存在门槛效应。他们利用1980-2010年的数据, 采用创新的动态面板國值技术对 87 个发展中和 发达国家金融发展和经济增长的关系进行了研究，结果表明，金融发展低于门槛（阈值）, 金融将对经济增长产生积极影响, 经济发展将随着金融发展的提高而增加; 如果金融发展超 
过门槛（阈值），金融对经济增长的影响将转为负值，进一步的金融发展不会转化为更高的 经济增长。而Ruiz（2018）采用动态面板门槛模型, 对116个工业化和发展中国家的1991-2014 年的数据进行了实证分析, 得出了相似的结论, 即金融发展低于阈值的国家经济增长较少, 高于阈值的国家经济增长较快; 在工业化经济体中，机构投资者对人均国内生产总值的增长 有积极的影响。

而Nahla Samargandi等 (2015) 认为, 在长期, 金融发展与经济增长之间存在倒U型关系。 而在短期，金融发展与经济增长之间的关系微不足道。他们采用集合平均群估计方法，对52 个中等收入国家1980-2008年的数据进行了分析, 通过估计门槛模型, 证实了金融发展对经济 增长的非单调效应，过多的金融发展对中等收入国家的增长可能产生负面影响。

但是在利用 88 个国家1981---2010年的数据, 采用面板门限模型进行了实证分析后, 杨洋 \&赵茂 (2016) 认为, 金融发展的经济增长效应存在双重门限的近似“斜S型”非线性结构形式, 适宜的金融发展水平是经济实现最优增长的重要条件。

此外，有研究者认为，金融发展对经济增长的作用存在国家间的差异。

Shan, Morris, Sun (2001) 分析了银行中介和经济增长之间的关系。利用10个国家1960-1998 年的数据, 通过带条件集的VAR分析方法, 结果表明, 5 个国家的银行中介和经济增长之间存 在相互促进的因果关系; 3 个国家存在经济增长促进银行中介发展关系, 即需求跟进假设成立; 2 个国家的银行中介和经济增长不存在因果关系。

Rioja \& Valev (2004) 采用广义矩量法 (GMM) 动态面板技术对74个国家进行了分析, 结果表明, 在较低的地区（金融发展水平很低的国家），金融市场的进一步改善对经济增长 的影响不确定; 在中间区域, 金融发展对经济增长有很大的积极影响。最后, 在高区域, 金 融发展对经济增长的影响效果是正面的, 但效果较小。

Henderson等 (2013) 对101个国家1960-2000年的数据, 采用非参数估计方法进行了分析 认为, 尽管在中等收入和高收入国家金融发展和经济增长之间的关系是显著的积极的, 并且 随着时间推移而变得更强, 但在决定低收入国家增长方面, 金融发展和经济增长之间的关系 是不存在的, 或只是起了很小的作用; 在低收入国家, 促进经济发展的最优战略是不应该发 展金融业。

Monica Andini \& Corrado Andini (2014) 利用78个国家1960-1995年的数据, 采用分位数 参数异质性模型进行了分析, 结果表明, 对于同样的金融发展刺激, 处于增长条件分布上尾 的国家比处于下尾的国家反应要大，即同一个金融发展政策对一个国家是有效的，而对另一 个国家可能是效果较小或是无效的。

Seven \&Yetkiner（2016）利用1991-2011年的数据, 采用广义矩量法（GMM）动态面板 技术和主成份分析方法, 对146个低收入、中等收入和高收入国家间金融发展和经济增长的关 系进行了分析, 结果表明, 在低收入和中等收入国家, 银行业发展对经济增长有显著的积极 影响, 在高收入国家, 银行业发展对经济增长有显著的负面影响; 在中等收入和高收入国家, 股票市场的发展和经济增长都是显著正相关的, 股票市场的发展对高收入国家的经济增长影 响更大。

Harris（1997）利用49个国家1980-1991年的数据, 实证分析了股票市场与经济增长之间 的关系。借助最小二乘回归分析法发现, 在高收入国家, 资本市场发展对经济增长仅有非常 有限的正相关关系。

\section{2 发达国家样本研究}

发达国家样本研究表明, 金融发展和经济增长之间的关系存在差异性。

有的学者认为，金融发展和经济增长之间存在相关性。如Rousseau \& Wachtel（1998）认 为, 在经济发展的早期阶段, 银行中介发展导致了经济增长, 即供给导向假设成立。他们的 研究样本是美国、英国、加拿大、瑞典和挪威1870-1929年的数据, 采用VAR框架下的格兰杰 因果分析方法。而Leahy等 (2001) 认为, 所有的金融部门对经济增长都有正的影响, 股市的 
影响是最大的。金融发展、良好的金融法律框架可以通过创新强化经济增长。他们利用 16 个 欧洲国家1970-1997年的数据，通过建立在ARDL模型上的面板误差修正方法进行分析。 Gerhard Fink等（2003）则将债券市场发展作为金融发展指标, 利用13个经济高度发达国家 1950-2000年的数据, 借助格兰杰因果检验和协整方法开展了实证研究。美国、英国、瑞士、 德国、奥地利、荷兰和西班牙7个国家的经验证据表明, 债券市场发展促进了经济增长, 即供 给导向假设是成立的。日本、芬兰和意大利 3 个国家经验证据表明债券市场和经济增长之间存 在相互促进关系。Pradhan等（2016）则进一步扩大了变量范围, 将债券市场发展、通货膨胀 率、实际有效汇率、实际利率以及对国际贸易开放程度作为自变量, 利用 35 个中等收入和高 收入国家1993-2011年的数据, 借助面板向量自回归模型, 证明债券市场发展以及其他宏观经 济变量是推动经济增长的长期因素。

但是也有研究者认为, 金融发展和经济增长之间关系不大。Arestis, Demetriades (1997) 利用美国和德国1979-1991年的季度数据, 通过系统性外生分析方法, 分析了银行中介和股票 市场与经济增长之间的关系。实证结果表明, 美国的金融部门和经济增长之间不存在单向因 果关系, 但德国的金融部门和经济增长之间存在因果关系。Rivaud-Danse, Dubocage, Salais

（2001）利用欧盟9个国家1990-1996年的数据，实证分析了投资回报增加值与自由资金杜杆、 金融债务结构、流动资本三个自变量的关系。借助聚类分析方法发现, 金融变量和工业业绩 之间没有相关性。Peia \& Roszbach（2015）利用22个发达国家1965-2011年的时间序列数据， 分析表明金融和增长之间的因果关系模式取决于金融发展是否来自银行部门或股票市场。具 体而言, 11 个国家的股票市场发展对经济增长产生了因果关系, 而16个国家的经济增长和银 行发展之间存在反向因果关系。

但是也有研究者在同一个样本中得出不同的结论。如Kugler, Neusser（1998）同样分析 股票市场和经济增长之间的关系, 但利用13个欧盟国家1960-1997年的数据, 借助格兰杰因果 检验方法，金融与实际部门之间的关系存在差异：美国、日本和德国三个国家存在正向因果 关系，部分国家存在负向因果关系，没有证据表明小国家存在因果关系。

\section{3 发展中国家研究样本}

Hugh T. Patrick（1966）通过研究欠发达国家的金融发展和经济增长之间的关系发现，金 融发展和经济增长之间存在两种关系，一是经济中投资和储蓄的需求导致金融体系的发展， 即金融发展是经济增长引致需求的结果，即需求跟进论（Demand-following）；二是金融部门 将储蓄配置给效率更高的部门以促进社会经济增长, 即经济增长是金融供给引导结果, 即供 给导向论 (Supply-leading)。作者检验了金融发展对经济增长的影响, 即通过影响实际资本存 量进而影响实际产出。金融体系通过三种路径影响实际资本存量：一是通过改变有形财富的 所有权和构成, 金融机构可以实现财富的有效配置; 二是通过调节储蓄和投资关系，金融机 构可以实现投资更有效率; 三是通过刺激储蓄、投资和工作，金融机构可促使资本积累率的 提升。

McKinnon（1973）研究了二战后阿根廷、巴西、智利、德国、韩国、印度尼西亚和台湾 的金融体系与经济发展之间的关系。从这些国家案例研究中涌现出来的大量证据表明, 运转 良好的金融体系支持更快的经济增长。

Darrat （1999）同样分析了银行中介和经济增长之间的关系，但是他利用的是沙特阿拉 伯、土耳其1964-1993年的年度数据, 阿联酋1973-1993年的年度数据, 借助向量误差修正模 型, 实证结果存在差异。土耳其和阿联酋的银行中介发展能够促进经济增长, 供给导向假设 得到强有力支持。在短期内, 沙特阿拉伯的银行中介和经济增长之间没有关系, 但是在长期 内，银行中介和经济增长之间存在相互存进的双向因果关系。

Muhsin Kar等（2011）用中东和北非15个国家1980-2017年的数据分析了金融发展和经济 增长的因果关系。借助近似不相关回归模型和抽取国家特定临界值的沃尔德测试法, 实证结 果表明，金融发展和经济增长之间并没有明确的因果关系。Menyah等（2014）利用21个非洲 
国家1965-2008年的数据就金融发展、贸易开放以及经济增长之间的因果关系进行了实证研 究。借助系统建模方法和主成份分析方法, 结果显示, 供给导向假设仅在 3 个国家成立; 需求 跟进假设仅在 1 个国家成立; 金融发展促进经济增长和贸易增长的假设绝大多数国家都不成 立；仅有非常有限的证据支持金融发展促进非洲国家经济增长的假设。

Bittencourt (2012) 对阿根廷、玻利维亚、巴西和秘鲁四国1980-2007年的数据进行了分 析, 结果表明, 金融发展在上述4个拉美国家经济增长起着重要作用。

Al-Yousif (2002) 利用30个发展中国家1970-1999年的数据, 借助误差修正模型和面板数 据法进行了实证分析，结果表明，银行中介与经济增长之间具有很强的双向因果关系。

P.K. Narayan，S. Narayan（2013）则利用65个发展中国家1995-2011年的数据分析了金融 发展对经济增长的短期影响。通过GMM方法, 全部面板数据结果表明, 金融发展促进了经济 增长, 但是银行信贷对经济增长有负面影响。中东国家的数据表明, 无论金融部门还是银行 部门都不利于经济增长; 除了亚洲国家外，金融发展对经济增长的作用较弱; 除了中东国家 外，银行信贷对经济增长具有显著的负面影响。

Khairulx Alom（2018）则将实际利率、私人部门信贷、M2、贸易开放、股票市场总价值 作为金融发展指标，利用南亚5国1985-2014年的数据，通过向量自回归模型、方差分解、脉 冲响应函数以及完全修正的最小二乘法进行了实证分析, 结果表明, 金融发展与经济增长长 期具有协整关系, 即实际利率、M2、贸易开放度、私人部门信贷、股票交易总价值与长期经 济增长之间存在协整关系。

\section{3. 单一国家样本研究}

\section{1 其他单一国家样本研究}

Hansson等（1997）用瑞典1834-1991年的数据，通过协整分析（人均投资是条件变量） 方法, 分析了银行中介与经济增长之间的关系。实证结果表明, 银行中介与实际收入是协同 演化的。银行中介和产出之间的关系是不稳定的: 1890-1934年之间是供给导向关系, 即银行 中介发展带动了经济增长。

Harrison等（1999）基于理论分析以及美国各州经验数据实证分析证明，金融发展与经济 增长之间具有相互促进的关系。

Uddin等（2013）利用1971-2011年的数据分析了肯尼亚的金融发展和经济增长的关系。 基于柯布-道格拉斯生产函数, 借助ARDL边界测试和Gregory-Hansen's变结构协整检验方法, 结果发现，从长期看，金融业的发展对经济增长有积极影响。

Jedidia等(2014)采用回归分布滞后模型（ARDL）分析了1973---2008年间突尼斯金融发展 与经济增长之间的关系。实证结果表明, 突尼斯金融部门发展与经济增长有着长期的因果关 系，即金融部分发展将促进经济增长。

Yener Coşkun等（2017）利用土耳其2006年1月-2016年1月的月度数据，分析了资本市场 与经济增长的关系。借助 ARDL模型、马尔可夫转换回归模型和卡尔曼滤波模型, 实证结果 表明, 资本市场发展和经济增长存在一个长期单向因果关系, 即资本市场发展能够存进经济 增长; 但是资本市场发展对经济增长的影响是非对称的, 国债市场的发展对经济增长的影响 是负面的，其他证券市场的发展对经济增长的影响是积极正向的。

Adeniyi等（2015）使用了1960-2010年的年度数据，利用门槛模型，分析了尼日利亚金融 发展与经济增长的非线性关系。结果表明, 金融发展对经济增长有负面影响, 但对门槛型效 应的影响则是一种符号反转。高辉 (2011) 利用中国1998-2009年的季度数据, 通过构建联立 方程模型, 利用GMM估计方法系统考察了中国的金融中介、股票市场与经济增长之间的相互 关系。实证研究结果表明, 金融中介发展与经济增长二者相互影响, 但作用方向不同: 金融 中介的总体规模对经济发展的影响为负; 经济增长对于金融中介的发展存在显著的正向作用; 
股票市场发展与经济增长二者相互之间的影响并不显著; 从金融中介发展与股票市场发展的 相互关系来看，股票市场发展对金融中介发展有较大促进作用，但金融中介发展对股票市场 发展的作用不明显。田卫民（2017）利用中国1995-2014-年中国省际经验数据, 进一步研究 金融发展和经济增长的关系，结果表明，金融发展抑制了地区经济增长，金融发展不仅降低 了全要素生产率，而且降低了资本积累率，从而对经济增长产生了负向影响。中国的经济增 长主要依赖于资本形成和劳动力投入, 对外开放、城市化、教育以及基础设施建设促进了经 济增长，财政支出则抑制了经济增长。

\section{2 中国样本研究}

关于中国金融发展和经济增长关系研究分两类，一是研究者认为金融发展和经济增长之 间存在线性关系; 一是研究者认为金融发展和经济增长之间存在非线形关系。

3.2.1金融发展和经济增长之间存在线性关系

谈儒勇（1999）运用OLS进行线性回归研究了中国金融中介和股票市场发展与经济增长 的关系, 结果表明, 中国金融中介体发展和经济增长之间有显著的、很强的正相关关系; 中 国股票市场发展和经济增长之间有不显著的负相关关系。

李钊等（2006）采用两部门模型，对中国1978-2002年的数据进行了分析，结果表明， 以 $\mathrm{M} 2$ 为测度指标的金融发展与经济长的正向关系, 并且金融发展是经济增长的 Granger 原 因。

3.2.2金融发展和经济增长之间存在非线性关系

第一，部分学者证明中国的金融发展和经济增长之间存在非线性关系。如Chen, $\mathrm{Wu}$, Wen（2013）借助门槛模型, 通过分析中国28个省份1978---2010年的数据进行了实证分析。 结果表明, 金融对高收入省份的增长有很强的正面影响, 但对低收入省份的增长产生了强烈 的负面影响。证明中国金融发展和经济增长之间存在非线性关系。刘金全, 解瑶姝（2016） 以我国2006---2014年的省级季度面板数据作为支撑, 选取了更具实际应用价值的内生增长理 论中的相关模型, 以金融相关率为转移变量, 基于PSTR模型就我国金融发展对经济增长的作 用机制进行了实证研究, 得出了我国金融发展对经济增长的作用具有复杂的非线性迁移性影 响的结论。谢平安等 (2017) 利用面板平滑转换模型, 同样证明金融发展对经济增长表现为 非线性效应。

第二, 部分学者认为中国金融发展与经济增长之间存在U形关系。如姚耀军，鲍晓辉 （2013）基于1994---2010年中国省级面板数据，利用双向固定效应计量模型发现，金融中介 发展与经济波动幅度呈显著的倒U形关系，金融中介发展对货币冲击具有显著的减震效应。 金融中介发展不是中国宏观经济运行平稳度显著提高的一个主要原因。李强, 李书舒 (2017) 也得出了金融发展和经济增长之间存在倒U形关系。而彭俞超, 朱映惠, 顾雷雷（2017）则 认为中国金融发展对经济增长的促进作用存在U型的时间结构特征。基于中国 1990-2014年 的动态面板数据, 运用系统GMM估计就财政支出和金融发展对经济增长的影响进行实证分 析，结果表明，财政支出和经济增长之间存在显著的“倒U型”关系; 金融发展对经济增长的影 响同样存在显著的“倒U型” 效应; 在经济相对发达的沿海地区, 市场化的金融手段可以更好地 促进经济增长, 而在经济相对落后的内陆地区, 由于金融发展水平相对滞后, 经济增长更多 地依赖财政投入。

第三，部分学者认为中国金融发展与经济增长之间存在门限值（阈值）。如张珂等 (2009) 采用Hansen（1999）平行数据阈效应模型的检验与估计方法, 利用改革开放以来中国28个省 份的数据, 实证结果表明, 经济发展水平是影响金融发展与经济增长关系的一个重要的阈变 量。在经济发展水平高的地区, 金融发展促进了经济增长; 在经济发展水平低的地区, 金融 发展阻碍了经济增长; 在经济发展水平中等的地区, 金融发展不能用来解释经济增长。研究 还表明，通货膨胀率和开放程度在金融发展与经济增长的阈效应并不明显。黄智淋，董志勇 （2013）采用我国31个省市1979-2008年的年度面板数据, 以通货膨胀率为门限变量, 运用动 
态面板数据门限模型进行了实证分析, 研究结果表明, 金融发展与经济增长之间的关系存在 通货膨胀率门限效应, 通货膨胀率门限值约为 $5.05 \%$ 左右; 当通货膨胀率低于门限值时, 金融 发展与经济增长是正相关的; 而当通货膨胀率超过门限值时，金融发展与经济增长是负相关 的。赵炜涛 (2016) 利用2000年-2013年中国省际面板数据, 采用 Hansen双门槛效应回归方 法来研究金融发展与经济增长的非线性关系。实证研究结果表明, 金融发展规模在金融发展 效率和经济增长的双重约束下会对经济增长存在双重门槛效应, 并且金融发展规模只有当经 济增长和金融发展效率超过一定的门槛值时才会对经济增长起到显著的促进作用, 在低水平 阶段则相反。李健, 盘宇章（2017）基于1998-2014年期间中国30个地区的平衡面板数据, 采 用DEA-Malmquist指数法以及动态面板模型, 将金融发展和实体部门经济之间的增长差异与 金融发展的交互项纳入到实证模型中，研究结果表明，金融发展和TFP增长之间具有非线性 关系，即金融发展对TFP增长的影响取决于金融发展和实体部门经济发展之间的增长差异。 当金融发展增速超过实体部门经济增速的 $54.5 \%$ 时, 金融发展抑制TFP的增长; 当金融发展增 速与实体部门经济增速之间的差异低于 $54.5 \%$ 时，金融发展会促进TFP的增长。

\section{4. 结束语}

从Schumpeter (1912) 提出金融发展能够促进经济增长观点以来, 很多学者从不同角度, 采用不同方法, 就金融发展与经济增长之间的关系开展了深入的研究, 但是目前为止, 并没 有形成一个统一的结论, 究其原因, 如下所示。

第一, 变量选取不同。从研究文献看, 研究者们从五个角度研究金融发展与经济增长的 关系。

一是从金融中介角度, 大多是银行, 研究银行发展与经济增长的关系, 如King \& Levine （1993）、Al-Yousif（2002）、Hahn（2002）、Dilek Durusu-Ciftci等（2017）；也有学者将 保险公司、共同基金、养老金等机构投资者作为金融发展的变量, 研究金融发展和经济增长 的关系，如Ruiz（2018）。

二是从金融市场发展角度研究金融发展与经济增长的关系，如Harris（1997）、Kugler \& Neusser (1998) 等研究股票市场发展与经济增长的关系; 也有学者研究债券市场发展与经济 增长的关系，如Gerhard Fink等（2003）。

三是将宏观经济变量纳入到金融发展指标，研究金融发展与经济增长的关系。如 Rivaud-Danse \& Dubocage \& Salais (2001) 研究投资回报增加值与自由资金杜杆、金融债务 结构、流动资本三个自变量的关系; Pradhan等 (2016) 研究债券市场发展、通货膨胀率、实 际有效汇率、实际利率以及对国际贸易开放程度与经济增长; Khairulx Alom（2018）研究实 际利率、私人部门信贷、M2、贸易开放、股票市场总价值与经济增长的关系。

四是将金融中介发展与金融市场发展共同纳入到变量中，研究金融发展与经济增长的关 系。如Leahy等（2001）、Seven\&Yetkiner（2016）、DilekDurusu-Ciftci等（2017）研究者们的 研究。

五是理论模型构建并实证检验。如Lucas（1988）。

基于上述研究角度的不同, 因变量的指标主要是人均GDP, 自变量的指标选取上存在差 异。以银行发展与经济增长关系研究为例。King, Levine (1993) 选取流动资产/GDP、私人 信贷/GDP、私营企业信贷/GDP、（商业银行+中央银行资产）/GDP作为自变量, 以产出增长、 资本存量增长和生产率增长作为因变量, 研究银行中介和经济增长关系; 而Rousseau, Wachtel

（1998）则以基于银行存款和信贷的各种中介提供的基础货币为自变量, 以人均GDP增长为 因变量, 研究银行中介和经济增长关系; Darrat（1999）、Al-Yousif（2002）则以货币比率 $\mathrm{M}_{1} / \mathrm{GDP}$ 和广义货币速度 $\mathrm{M}_{2} /$ 名义GDP为自变量, 人均实际GDP增长为因变量, 研究银行中介 和经济增长关系; Shan, Morris, Sun (2001) 以 (中央银行和存款银行的信贷) /GDP为自变 量, 以人均实际GDP为因变量, 研究银行中介和经济增长关系。 
第二，实证模型不同。从目前研究文献看，就金融发展和经济增长关系研究的实证模型 主要有面板线性回归模型、最小二乘回归分析法、VAR框架下的格兰杰因果分析方法、向量 误差修正模型、ARDL模型上的面板误差修正方法、带条件集的VAR分析方法、门槛回归模 型、用广义矩量法 (GMM) 动态面板技术、非参数估计方法、分位数参数异质性模型、动态 面板阈值技术、半参数局部线性模型、元分析技术、动态面板门槛模型、PSTR模型、 DEA-Malmquist指数法以及动态面板模型等。这些实证模型对变量的估计方法存在一定的差 异。

基于上述分析，关于金融发展与经济增长关系的研究呈现出不同的研究结果。但总体而 言，国家之间经济发展状态是不同的，同一国家不同区域的经济发展也存在差异，金融发展 和经济增长之间的关系一定也存在差异，既可能是线性关系，也可能是非线性关系，甚至是 没有关系。因此, 深化已有的金融深化理论、金融抑制理论以及经济增长内生理论有助于拓 展现有研究。

\section{致谢}

本文为2017年上海高校教师专业发展工程项目、2017年上海高校示范性全英语教学课程 《投资学 (CFA) 》以及 2017 年上海市重点课程《投资学》资助成果。

\section{References}

[1] Schumpeter J A..The theory of economic development,Cambridge,MA:Harvard University Press, 1912.

[2] Ang J. B..A Survey of Recent Developments in the Literature of Finance and Growth,Journal of Economic Surveys,vol. 22(3),pp. 536-76,2008.

[3] Gerhard Fink,Peter Haiss,Sirma Hristoforova. Bond Markets and Economic Growth,IEF Working Paper No. 49,April 2003 https://core.ac.uk/download/pdf/11007252.pdf

[4] Rudra P. Pradhan,Mak B. Arvin,Sara E. Bennett,Mahendhiran Nair,John H. Hall.Bond Market Development, Economic Growth and Other Macroeconomic Determinants: Panel VAR Evidence,Asia-Pacific FinancialMarkets,vol. 23,pp. 175-201,2016.

[5] Jiang chun, Su zhiwei. How financial development promotes economic growth -- a literature review,Financial research,vol. 9.pp. 110-122,2013.

[6] Yu chengyong. Relationship between financial development and economic growth: direction and structure difference ---- meta-analytical evidence from global Banks and stock markets, Nankai economic research,vol. 1,pp. 33-57,2016.

[7] Xie ping, et al. Nonlinear effect of financial development on economic growth ---- an empirical study based on panel smooth transition model,Regional finance research,vol. 3,pp. 36-47,2017.

[8] Goldsmith, R. W..Financial Structure and Development,New Haven: Yale University Press, 1969.

[9] King, R.G., Levine, R.. Finance and Growth: Schumpeter Might Be Right,The Quarterly Journal of Economics,vol. 108(3),pp. 717-737,1993.

[10]Levine, R., Loayazaeck, T.. Financial intermediation and growth: causality and causes,Journal of Monetary Economics,vol. 46(1),pp. 31-77,2000.

[11]Levine, R., Zervos, S..Stock markets, bank, and economic growth,American Economic Review,vol. 88(3),pp. 537-558,1998. 
[12]Dilek Durusu-Ciftci,M.Serdar,Hakan Yetkiner.Finacial Development and Economic Growth: Some Theory and More Evidence,Journal of Policy Modeling,vol. 39(2),pp. 290-306,2017.

[13]Berthélemy, J.C., Varoudakis, A..Financial Development and Growth Convergence: A Panel Data Approach, in Hausmann, R., H.Reisen (eds.),Promoting Savings in Latin America,Paris: OECD,pp. 35-69,1997.

[14]P.K. Narayan,S. Narayan.The short-run relationship between the financial system and economic growth: New evidence from regional panels,International Review of Financial Analysis,vol. 29(9),pp. 70-78,2013.

[15]Hahn, F.R.. The Finance-Growth Nexus Revisited,New Evidence From OECD Countries,Austrian Institute of Economic Research, WIFO Working Papers, No.176,2002.

[16]Cao qiang, Does financial development promote economic growth? ---- analysis based on semi-parametric model,Journal of Nanjing Normal University (social science edition),vol. 3,pp. $65-75,2014$.

[17] Siong Hook Law,Nirvikar Singh.Does too much finance harm economic growth?,Journal of Banking \&Finance, vol. 41(4),pp. 36-44,2014.

[18]Jose L.Ruiz.Financial development, institutional investors, and economic growth,International Review of Economics \&Finance,vol. 54(3),pp. 218-224,2018.

[19]Nahla Samagandi,Jan Fidrmuc,Sugataghosh.Is the Relationship Between Financial Development and Economic Growth Monotonic? Evidence from a Sample of Middle-Income Countries, World Dvelopment,vol. 68(4),pp. 66-81,2015.

[20] Yang Yang, Zhao mao. Economic growth effect of financial development: linear or nonlinear -a transnational empirical study based on panel threshold model,Modern finance and economics (Journal of Tianjin University of Finance and Economics),vol. 8,pp. 28-35,2016.

[21]Shan, J.Z., Morris, A.G., Sun, F.. Financial Development and Economic Growth: An Egg-and-Chicken Problem?,Review of International Economics, vol. 9(3),pp. 443-454,2001.

[22]Felix Rioja,Neven Valev. Does one size fit all?: a reexamination of the finance and growth relationship,Journal of Development Economics,vol. 74(8),pp. 429-447,2004.

[23]Daniel J.Henderson,Chris Papageorgiou,Christopher F.Parmeter. Who benefits from financial development?New methods,new evidence,European Economic Review,vol. 63(C),pp. 47-67,2013.

[24]M. Andini, C. Andini.Finance, growth and quantile parameter heterogeneity,Journal of Macroeconomics,vol. 40(1),pp. 308-322,2014.

[25] Ünal Seven, Hakan Yetkiner.Financial intermediation and economic growth: Does income matter?,Economic Systems,vol. 40(3),pp. 39-58,2016.

[26]Harris, R.D.F..Stock Markets and Development: A Re-assessment,European Economic Review,vol. 41(1),pp. 139-146,1997.

[27]Rousseau P.L.Wachtel, P. .Financial Intermediation and Economic Performance: Historical Evidence from Five Industrialized Countries,Journal of Money, Credit and Banking,vol. 30(4),pp. 658-678,1998.

[28]Gerhard Fink,Peter Haiss,Sirma Hristoforova. Bond Markets and Economic Growth, IEF Working Paper No. 49,April 2003 https://core.ac.uk/download/pdf/11007252.pdf 
[29]Rudra P. Pradhan,Mak B. Arvin,Sara E. Bennett,Mahendhiran Nair,John H. Hall.Bond Market Development, Economic Growth and Other Macroeconomic Determinants: Panel VAR Evidence,Asia-Pacific Financial Markets,vol. 23(2),pp. 175-201,2016.

[30]Philip Arestis,Panicos Demetriades.Financial Development and Economic Growth: Assessing the Evidence,The Economic Journal,vol. 107(442),pp. 783-799,1997.

[31]Rivaud-Danset D., Dubocage, E, Salais, R..Comparison between the financial structure of SMES and that of large enterprises (LES) using the BACH database,European Economy Economic Papers 2008 - 2015 155, Directorate General Economic and Financial Affairs (DG ECFIN), European Commission,2001.

[32] Oana Peia,Kasper Roszbac.Finance and growth:Time series evidence on causality,Journal of Financial Stability,vol. 19(8),pp. 105-118,2015.

[33]Kugler, M., Neusser, K.. Manufacturing Growth and Financial Development: Evidence from OECD Countries, The Review of Economics and Statistics, vol. 80(4),pp. 638-646,1998.

[34]Hugh T. Patrick. Financial Development and Economic Growth in Underdeveloped Countries,Economic Development and Cultural Change,vol. 14(2),pp. 174-189,1966.

[35]Mckinnon, R. I.. Money and Capital in Economic Development,Washington, D. C.: Brookings Institution, 1973.

[36]Darrat.A.F.. Are financial deepening and economic growth causally related? Another look at the evidence,International Economic Journal,vol. 13(3),pp. 19-35,1999.

[37]M. Kar,S. Nazlığlu,H. Ağır.Financial development and economic growth nexus in the MENA countries: Bootstrap panel Granger causality analysis,Economic Modeling,vol. 28(1-2),pp. 685-693,2011.

[38]Kojo Menyan,Saban Nazlioglu,Yemane Wolde_Rufael.Financial development, trade openness and economic growth in African countries: New insights from a panel causality approach,Economic Modelling,vol. 37(2),pp. 386-394,2014.

[39] M. Bittencourt.Financial development and economic growth in Latin America: Is Schumpeter right?,Journal of Policy Modeling,vol. 34(3),pp. 341-355,2012.

[40]AL-Yousif, Y..Financial development and economic growth: another look at the evidence from developing countries, Review of Financial Economics, vol. 11(2),pp. 131-150,2002.

[41]Khairulx Alom.Financial Development And Economic Growth Dynamics In South Asian Region, The Journal of Developing Areas,vol. 52(4),pp. 47-66,2018.

[42]Hannson, P., Jonung, L..Finance an Economic Growth: The Case of Sweden,Research in Economicsol.vol. 51(3),pp. 251-301,1997.

[43]Uddin, Gazi Salah \& Sjö, Bo \& Shahbaz, Muhammad.The causal nexus between financial development and economic growth in Kenya,Economic Modelling,vol. 35(C),pp. 701-707,2013.

[44]Khoutem Ben Jedidia,Thouraya Boujelbenec,Kamel Helalid.Financial development and economic growth: New evidence from Tunisia,Journal of Policy Modeling,vol. 36(5),pp. 883-898,2014.

[45]Yener Coşkun, Ünal Seven, H. Murat Ertuğrul, Talat Ulussever. Capital market and economic growth nexus: Evidence from Turkey,Central Bank Review,vol. 17(3),pp. 19-29,2017. 
[46]Olwatosin Adeniyi,Abimbola Oyiniola,Olusegun Omisakin,Festus O. Egwaikhide.Financial development and economic growth in Nigeria:Evidence from threshold modelling,Economic Analysis and Policy,vol. 47(9),pp. 11-21,2015.

[47]Gao hui. Financial intermediation, stock market and economic growth: an empirical analysis based on simultaneous equation model,Shanghai economic research,vol. 2,pp. 11-19,2011.

[48] Tian weimin. Why financial development inhibits economic growth ---- empirical evidence from China's inter-provincial panel data,Economic issues,vol. 1,pp. 27-32,2017.

[49]Tan Xuyong.An empirical study on the relationship between financial development and economic growth in China,Economic research,vol. 10,pp. 53-61,1999.

[50]Li Zhao, Li Guoping, Wang Shujian.Financial development and economic growth: an empirical study of China based on the two-sector model,Southern economics,vol. 4,pp. 32-40,2006.

[51]K.C.Chen,Lifan Wu,Jian Wen.The relationship between finance and growth in China,Global Finance Journal,vol. 24(1),pp. 1-12,2013.

[52]Liu Jin-quan, Xie Yaoshu.Research on the nonlinear action mechanism of Chinese financial development on economic growth,Nanjing social science,vol. 3,pp. 8-16.2016.

[53]Yao Yao-jun, Bao Xiao-hui.Has the development of financial intermediaries smoothed economic fluctuations? ---- empirical evidence from China,Financial research,vol. 1,pp. 61-81,2013.

[54]Li Qiang, Li Shushu.The influence of fiscal expenditure and financial development on economic growth: nonlinear effect and correlation mechanism,Finance and trade research, vol. 2,pp. 21-29,2017

[55]Peng Yuchao, Zhu Yinghui, Gu Leilei.Structural effects of financial development on economic growth -- based on meta-regression analysis,Nankai economic research,vol. 5,pp. 20-36,2017.

[56]Zhang Ke, Yan Dan, Fu Yong.Research on threshold effect of financial development and economic growth in China -- empirical evidence from parallel data of Chinese provinces and cities ,Shanghai finance,vol. 10,pp. 11-16,2009.

[57]Huang Zhilin, Dong Zhiyong.Nonlinear relationship between financial development and economic growth in China ---- empirical evidence from dynamic panel data threshold model,Financial research,vol. 7,pp. 74-86,2013.

[58]Zhao Weitao.Nonlinear relationship between financial development and economic growth ---double threshold effect based on China's inter-provincial panel data,Journal of graduate students, zhongnan university of economics and law,vol. .2,pp. 34-41,2016.

[59]Li Jian, Pan Yuzhang.Financial development, real sector and total factor productivity growth ---- analysis based on Chinese provincial panel data,Economic science,vol. 5,pp. 16-30,2017.

[60]Khairulx Alom.Financial Development And Economic Growth Dynamics In South Asian Region, The Journal of Developing Areas,vol. 52(4),pp. 47-66,2018. 